\title{
Chapter \\ Social Theory, Psychiatry and Mental Health Services
}

\author{
Rob Poole and Catherine Robinson
}

\section{Introduction}

This chapter describes the development of social concepts within psychiatry and mental services between 1960 and 2010 and the impact of the new ideas developed within social sciences at the time. Concepts and movements considered include deinstitutionalisation; therapeutic communities; Community Mental Health Teams (CMHTs); social constructionism; labelling theory; social functionalism; paradigm shift; stigma; the service user movement; and the social determinants of mental health. There was tension between new postmodernist ideas and the positivist-scientific model that underpinned both social psychiatry of the period and confident, and ultimately hubristic, advocacy of the primacy of neuroscience in psychiatry during 'the Decade of the Brain'. Although some new ideas were eventually assimilated by psychiatry, the tension was unresolved in 2010 .

\section{Social Thinking in Psychiatry in 1960}

In 1960, the social perspective was prominent within British mental health services. A subdiscipline of social psychiatry had been forming for some time and many of its enduring themes were already evident. British psychiatry had needed to change rapidly as a consequence of the social, political and economic impact of the Second World War and its aftermath. Mental hospitals, which previously had been the responsibility of local authorities, were absorbed into the new National Health Service (NHS) in 1948 and deinstitutionalisation commenced almost immediately, alongside changes in organisation, staffing and attitudes to treatment.

During the Second World War, psychological reactions to combat were regarded as a medical problem rather than as a matter of military discipline. A relatively small pool of psychiatrists was called upon to treat large numbers of service personnel suffering from 'battle fatigue' or 'effort syndrome', leading to pragmatic experimentation with group treatments. Necessity proved to be a virtue and new group-based social therapeutic modalities followed. At the Maudsley Hospital, Maxwell Jones developed the idea that the entire experience of living together could be therapeutic and, at Northfield Military Hospital, Tom Main coined the term 'therapeutic community', which became a banner under which many later reforms were made to inpatient care (sometimes less stridently labelled the 'therapeutic milieu').

There was a growing belief that, with support, people with chronic psychosis could have better lives in the community. There was optimism about new biomedical treatments, such as antipsychotic and antidepressant drugs, and electroconvulsive treatment. A degree of therapeutic heroism meant that there were some awful therapeutic mistakes too, such as 
deep sleep therapy (continuous narcosis) and insulin shock, which, when properly evaluated, were found to be dangerous and ineffective. Nonetheless, at the time there seemed to be a realistic possibility that NHS psychiatrists would soon be able to work from day hospitals (developed by Joshua Bierer at the Marlborough Day Hospital in London) and outpatient clinics, avoiding mental hospital admission altogether.

Social psychiatry was also ascendant in academia under the pervasive influence of Sir Aubrey Lewis at the Maudsley Hospital. Lewis was a social psychiatrist who had undertaken early anthropological research among Aboriginal Australians. He was influenced by Adolf Meyer's work in Baltimore (see also Chapter 2). The Institute of Psychiatry was formed at the Maudsley in 1946 under his leadership and in 1948 he became the first director of the Medical Research Council (MRC) Social Psychiatry Unit there. He retired in 1966, but his influence persisted long after he had gone, as did his brand of social psychiatry.

As the 1960s started, and for many years thereafter, organised British medicine, including social psychiatry, followed a theoretical model that went back to scientific medicine's Enlightenment origins. It was based upon the belief that positivism, reductionism and empiricism were the most powerful and meaningful ways of understanding mental disorders and that science itself was intrinsically subject to continuous progress. Fundamental causes of mental disorders were believed to be biological or psychological but social factors were recognised to influence their expression, course and outcome. Social psychiatry research mainly concerned itself with quantifying the impact of social environment and social interventions on mental illnesses, without challenging the fundamental assumptions of what came to be labelled 'the medical model'. Classic studies of the time (e.g. Wing and Brown's Three Hospitals study) ${ }^{1}$ exemplified social psychiatry's research approach; patients' symptoms and their social environment were assessed using operationalised criteria, the beginning of a long tradition of quantification through the use of symptom and social interaction rating scales.

A seminal 1963 study by Goldberg and Morrison addressed the possibility that social adversity might cause psychosis. ${ }^{2}$ It appeared to convincingly demonstrate that people with a diagnosis of schizophrenia drifted down the hierarchy of social class after they became ill, while unaffected family members did not. For many years, this 'social drift' was taken to account for known differences in prevalence between prosperous and deprived areas. It was not until the mid-1990s that new research methods started to shift the balance of evidence by showing that a variety of childhood adversities consistently increased the risk of adult psychosis. Psychiatry's resistance to the idea that social adversity might cause mental illness was such that, even in 2010, there was little sign that British psychiatrists were changing their thinking in response to the implications of newer research findings.

The positivist but eclectic scientific stance of mainstream British psychiatry meant that it readily adopted the biopsychosocial model proposed by Engel in the late 1970s and a version of it remained the explicit stance of organised British psychiatry until 2010 and beyond. ${ }^{3}$ Although a broad church of scientific and clinical orientations flourished within British psychiatry, psychiatrists remained highly protective of their status as leaders of mental health services and of research. They encouraged growth and development in mental health nursing, social work and clinical psychology, but they were insistent that their own profession was uniquely equipped to be in charge. ${ }^{4} \mathrm{~A}$ reluctance to take on new ideas about relative professional standing eventually weakened psychiatry's position when, from 1979 onwards, neoliberal politicians increasingly forced change upon it. 
Pilgrim and Rogers have suggested that, in 1960, psychiatry and sociology were in alliance with each other, using empiricism to understand the impact of social context on mental health. ${ }^{5}$ However, everything in social science was about to change. While empirical sociology never disappeared, a rift opened between the disciplines that was only just beginning to close again in 2010 .

\section{New Social Theories and the Reaction of British Psychiatry}

In Chapter 20, Burns and Hall refer to four books published in 1960/1 (Foucault's Madness and Civilisation; Laing's The Divided Self; Szasz's The Myth of Mental Illness and Goffman's Asylums) which were collectively the founding texts of so-called anti-psychiatry (a term rejected by the authors and later contested within social theory as serving to dismiss and marginalise valid critiques of psychiatry). They set out many of the themes that dominated social theory about mental health over the subsequent decades.

The new social theories had diverse origins and many variations developed. Those of the left came to be lumped together under the umbrella of 'postmodernism' (another label that was not wholeheartedly embraced by all of those it was applied to). The key theoretical positions about mental health were social functionalism, social constructionism and social labelling theory. Postmodernism tended to be concerned with the way that power is exercised and with privilege sustained through social and cultural institutions, language and ownership of knowledge. Many ideas were developed within a framework of neoMarxism (in particular, the work of Gramsci), but psychoanalytic ideas as applied to social interaction were also important. Few post-Second World War social theories ignored psychiatry, because many social scientists came to understand it as a key way in which society managed 'deviance' (in other words, the breaking of social rules).

Erving Goffman stood alone as a critic of mental health services who was well received by a significant proportion of psychiatrists. According to Goffman, mental hospitals were 'total institutions' where every aspect of life, activity and human interaction served to maintain control and subjugation of the patients. Far from being therapeutic, they were intrinsically oppressive and marginalising. This characterisation distressed some psychiatrists, who saw themselves as benign and caring, but an influential minority felt that Goffman had described something that concerned them too and that his ideas were helpful to programmes of deinstitutionalisation that they were leading.

Goffman's next project was on 'the spoiled identity' or stigma. According to social labelling theory, the ways that words that are used by psychiatry and society to describe mental illness, and the people so diagnosed, have a profound impact on both social attitudes to them and their sense of self. New concepts of stigma had an extensive and enduring impact, leading to successive campaigns for the use of less negative forms of language for mental illnesses and the people diagnosed with them (sometimes disparagingly labelled by opponents as 'political correctness'). The importance of stigma, and of reducing it, influenced mainstream psychiatry to the point where, in 1998, the Royal College of Psychiatrists mounted a five-year anti-stigma campaign.

Other new social theories proved more difficult for psychiatry to accept. Postmodernism held that mental illness had no existence independent of psychiatrists. It was seen as a social construct, which had developed to maintain order in the new urbanised society of the Industrial Revolution, justifying the sequestration of disruptive people in mental hospitals. This process was labelled 'the Great Confinement' by Foucault. British psychiatry rejected 
this as a denial of scientific facts and of human suffering and by 2010 had not reconciled itself to the idea.

The belief that the things that people diagnosed with schizophrenia said were intrinsically bizarre and non-understandable was a key element in Karl Jaspers's phenomenological approach to psychopathology, a cornerstone of British descriptive psychopathology. Laing and others strongly challenged this, insisting that the things people with psychosis said were intelligible if you took the trouble to understand the social and family context they existed within. Jaspers's influence weakened from the 1990s, mainly because of the application of cognitive behavioural ideas to the psychopathology of psychosis. Almost without acknowledgement, some of Laing's early ideas eventually gained acceptance (see also Chapter 20).

According to postmodernism, psychiatric practice, diagnosis and treatment could not be separated from the oppressive values of those who controlled society, especially sexism, racism and homophobia. Activists pointed out that women, people of black and other minority ethnic heritage, and gay people were more likely to receive a psychiatric diagnosis than male, white and heterosexual people. Professional ideologies were seen as intrinsically sexist, racist and homophobic. Diagnoses such as 'hysterical personality disorder' were condemned as sexist caricatures. Aversion therapies to change sexual orientation and the attribution of high rates of psychosis among black people to an intrinsic racial characteristic (rather than to social adversities, such as racism) were seen as value-laden and oppressive. From the mid-1990s, these ideas did begin to exert an influence on the way that psychiatry thought about itself, particularly as some urban CMHTs (see the section 'Developments in Social Thinking In Psychiatry') developed links with the communities they served. There was also increasing evidence from psychiatric research that these critiques were valid.

To the four key books of 1960/1 identified by Burns and Hall (see Chapter 20) can be added Thomas Kuhn's The Structure of Scientific Revolutions, ${ }^{6}$ which was published in 1962. This highly influential book had nothing specific to say about psychiatry but it had implications for the certainty with which psychiatry defended its positivistic roots. Kuhn's central thesis was that science does not progress smoothly following immutable and irreducible principles. Instead, 'normal science' operates within a constructed meta-model or paradigm. Over time, conflicting evidence accumulates that cannot be reconciled within the paradigm and eventually there is a paradigm shift, whereby all previous assumptions and ways of thinking about scientific problems are revised or dismissed, with the formation of an entirely new paradigm of greater explanatory power. 'Normal science' then proceeds within the new paradigm until it, in turn, is replaced. The implication for psychiatry was that its methods and models of science (and, by extrapolation, the profession's status) were neither timeless nor self-evident. Kuhn lent support to the postmodernist concept that psychiatry found most unpalatable: the suggestion that the objectivity of psychiatric science was illusory and rested upon a medical model that was a poor fit for psychological distress. The medical model could only, it was suggested, reflect psychiatrists' perception of 'truth'. Psychiatrists' understanding of mental disorder had no intrinsic claim to greater legitimacy than their patients' or anybody else's. By 2010, this concept was still fiercely resisted by psychiatry, despite a growing acceptance, at least theoretically, that there was value in social science qualitative research techniques that captured lived experience.

As postmodernism became increasingly influential, the gap between sociology and psychiatry widened. The scope of critiques of the medical model became greater, particularly after the publication of Ivan Illich's Medical Nemesis: Limits to Medicine in 1976. ${ }^{7}$ The book opened with the statement 'The medical establishment has become a major threat to 
health' and went on to suggest that this involved three different types of iatrogenesis: clinical, social and cultural. The first referred to direct adverse effects of treatment, the second and third to a wider impact that has the effect of undermining people's ability to manage their own health.

In the later period, social theorists were especially influenced by Foucault. Pierre Bourdieu, widely considered the most influential social theorist of his time, built on Foucault's ideas to develop concepts about social and cultural capital that were relevant to the understanding of mental disorders. ${ }^{8}$ Unlike Foucault, Bourdieu regarded empirical evidence as important. Nonetheless, his ideas only influenced a small minority of social psychiatrists. Later still, Nikolas Rose developed Foucault's concept of governmentality to explore the impact of the 'psy disciplines' beyond people diagnosed with mental disorder. ${ }^{9}$ He suggested that these disciplines (or industries) had had a profound role in forming general ideas about self, autonomy, control and authority for the entire population. Through the whole of our period of interest, UK psychiatry reacted negatively to postmodern critiques. Eventually, the relationship between sociology and psychiatry was distant, if not actively hostile.

The social theories of the new left challenged all the institutions of liberal democracy, but they were not the only intellectual movements that did so. Szasz, for example, was a rightwing libertarian who objected to the restriction of individual liberty by the state. To Szasz, compulsion had no role in helping people who were emotionally distressed. Indeed, the state itself had no legitimate role. The only legitimate relationship between psychiatrist and patient was an individual commercial transaction, freely entered into by both parties. Similarly, in economics, a challenge to the institutions of liberal democracy was forming on the right from neoliberals influenced by political economists such as Friedrich Hayek and Milton Friedman. ${ }^{10}$ In its purest form, neoliberalism came to see post-Second World War social welfare provision as a structural impediment to the workings of a free market which, if unfettered, would resolve social problems through perfectly expressed individual self-interest. These free market libertarian concepts became the economic orthodoxy of the second half of our period. They had a vicarious impact on psychiatry through the progressive marketisation of British health care following the NHS reforms of 1990 (see also Chapter 12).

\section{Developments in Social Thinking in Psychiatry}

While there was tacit acceptance of elements of new social theories in the later period, organised psychiatry mostly stood aloof and saw little reason to examine its own legitimacy. Postgraduate curricula and standard textbooks made scant reference to the new social theories. In 1976, a young Irish psychiatrist working at the Maudsley Hospital, Anthony Clare, published a book in defence of psychiatry, Psychiatry in Dissent. ${ }^{11}$ The book sought to refute anti-psychiatry and the new social theories on empirical grounds. To the profession, the exercise was satisfying and successful, but to psychiatry's critics, Clare missed the point. Having rejected the primacy of positivist science, a defence on that basis could not be convincing to them. On the other hand, academic mental health nursing, which developed rapidly from the mid-1980s onwards, embraced the new theories much more readily. Over time, nurses came to dominate mental health service management. By this route, postmodernist ideas came to have an impact on psychiatry from within services but from outside of the profession. 
Despite resistance to postmodernism, from 1960 to 2000 service innovation was led by social psychiatry. From 1962, Maxwell Jones applied therapeutic community principles to the entire mental health service at Dingleton Hospital in Scotland (see also Chapter 2). The result was the earliest version of the CMHTs. Twenty years later, alongside efforts to suppress the use of stigmatising language, specialist services started to emerge for women, for black and other minority ethnic groups and (mainly in response to the HIV epidemic) for gay people. These new services tended to accept that systematic disadvantage and discrimination were relevant to people's mental health and actively acknowledged this. Psychiatrists started to actively engage with these communities and more collaborative approaches developed. As usual, these developments were piecemeal and many services remained unreconstructed. Attitudes among younger psychiatrists changed, but this was probably a consequence of shifts in values among the educated middle class in general.

A major factor that eventually influenced all of the mental health professions was the mental health service user movement (see also Chapter 13). This had roots outside of health services and universities. It developed in the wake of the other liberation movements as part of the radical 'underground' of the 1960s and 1970s. It was a broad movement that varied in its attachment to critiques of, and hostility towards, psychiatry. Despite marked differences, the movement had some generally agreed-upon objectives: that service users should have choices in, and agency over, their treatment; that they should be involved in planning services and in developing research; that mental health assessment should take into account their full circumstances; that talking therapies should be as available as medication; that mental disorder should not be regarded as lifelong; that the aim of treatment should be recovery, defined by the patient; and that services should avoid stigmatising its users. By 2010, few service users felt that these objectives had been achieved, but they were accepted as legitimate and desirable by most mental health service managers and psychiatrists. From the 1990s, psychiatrists were pressed by governmental policies such as the Care Programme Approach and National Service Frameworks to conform to some of the service user movement's demands. In the later period, this led to major changes in the way that psychiatry was practised in the UK. For example, in 2010, many services claimed to follow 'the Recovery Model', albeit amid some controversy over ownership of 'recovery'.

\section{'The Decade of the Brain'}

Prompted by industry lobbying in the wake of the huge success of a new antidepressant, Prozac (fluoxetine), US president George H. W. Bush declared the 1990s to be 'the Decade of the Brain'. This had international ramifications and academic social psychiatry went into sharp decline. There was a massive biomedical research and development effort and new medications appeared that were claimed to be more effective, with fewer side effects, than the older ones. Advances in molecular genetics and brain imaging technologies created an expectation that the limitations of psychiatric treatment would be overcome by reference to 'fundamental' brain processes. New diagnostic categories appeared, generating suspicions that new markets were being created. There was less money available for social research in mental health and most of it was directed at trials of complex manualised community interventions such as 'assertive outreach'.

Optimism about biological advances in 'the Decade of the Brain' proved ill-founded. The new drugs proved no more effective and just as problematic as the old ones. Molecular genetics and new imaging techniques generated much new knowledge, but by 2000 there 
was no sign of any implementable technologies that might revolutionise psychiatric treatment. In fact, psychiatry had unwittingly confirmed some aspects of postmodernist critiques. It stood accused of having a deep and corrupt relationship with the pharmaceutic industry. Although organised psychiatry worked hard from the late 1990s onwards to distance itself from the industry, it was too late to undo the reputational damage. Intense attention to 'fundamental' biological processes had proven as fruitless as postmodernism had predicted.

Postmodernism did influence psychiatry in other parts of the world. For example, in Italy, neo-Marxist and Foucauldian theories underpinned Franco Basaglia's Psichiatria Democratica movement. Basaglia was a professor of psychiatry in Trieste. He was influenced by visiting Dingleton in the 1960s, and in 1978 his movement was successful in getting Law 180/78 enacted throughout Italy, banning mental hospital admissions and introducing a system of community care. The UK saw no corresponding positive response to new social theories until, in 2001, Bracken and Thomas heralded the development of a postmodern psychiatry (which they labelled 'post-psychiatry') with an article in the British Medical Journal $(B M J) .{ }^{12}$ Bracken and Thomas were part of the broader Critical Psychiatry Network, a group of radical psychiatrists. Unlike the medically qualified anti-psychiatrists of the 1960s, they insisted that they remained within the umbrella of the psychiatric mainstream, but the impact of their various conceptual threads varied. Their concerns over the medicalisation of life were widely shared, but post-psychiatry per se enjoyed little general support, possibly because of its use of the dense and unfamiliar language of postmodernism.

\section{Other Social Theory Developments}

From 2000, disillusionment with the claims of 'the Decade of the Brain' set in and social psychiatry gradually revived. Interest started to grow in the social determinants of mental health, due to the work of empirical researchers from public health and sociology such as Michael Marmot and Richard Wilkinson and the emerging epidemiological evidence that childhood deprivation related to psychosis more as a causal factor than a confounding factor. ${ }^{13}$ These findings implied the possibility of preventing mental ill health through social and public health intervention. Linked to this, there was increasing interest in global mental health, whereby international socio-economic factors were seen to have a disproportionate impact on the mental health of people in low- and middle-income countries, who were the majority of humanity.

A range of other social theories were little noticed by mainstream psychiatry but had some impact on specific therapies. For example, cybernetics and systems theory were applied to systemic family therapy. This was seen to be a powerful technique but attracted little interest beyond child and adolescent psychiatry. New ways of understanding social networks developed but they were rarely adopted in psychiatric research, and similarly concepts concerning social capital had little impact on psychiatry's understanding of inequality.

There are other examples, but the point is clear. Complex ways of understanding inequality and social context were hard to absorb into psychiatry's medical model, despite signs of a renaissance of interest in social factors by 2010. Writing at the end of the period, we pointed out that the biopsychosocial paradigm could not accommodate the contradictions in the evidence about mental health problems and that we appeared to be awaiting a scientific paradigm shift. ${ }^{14}$ 


\section{Conclusion}

While postmodernism and other social theories had a limited direct impact on the way that organised psychiatry understood social context and its own role in society, an indirect impact was felt as the years passed. This was due mainly to external influences such as the service user movement and assertive nurse-led management of mental health services. Later empirically based work had some traction on psychiatry, but at the end of our period, notwithstanding signs of revival, social psychiatry remained significantly less influential than it had been fifty years earlier.

\section{Key Summary Points}

- This chapter describes the development of social concepts within psychiatry and mental services between 1960 and 2010. This occurred against the backdrop of the emergence of new social theories concerned with psychiatry, medicine, science and other institutions of liberal democracy from the very beginning of the period.

- Attacks on the legitimacy of psychiatry came from postmodernists on the left and neoliberals on the right and coincided with a distancing between psychiatry and sociology.

- Organised psychiatry reacted defensively to most, but not all, of its critics and had difficulty assimilating even those new social theories that appeared neutral regarding the professional and scientific status of psychiatrists.

- From the 1990s, mental health nursing become dominant in a newly empowered NHS management, and the service user movement was successful in its campaigns to have key demands included in national and local government policy. These external influences forced change upon psychiatry.

- In the last decade of the period, empirical evidence regarding social determinants of mental health, together with the failure of biomedical technology to deliver on promises of better treatments, led to the beginnings of a revival of interest in social factors within academic psychiatry.

\section{Notes}

1. J. K. Wing and G. W. Brown, Social treatment of chronic schizophrenia: A comparative survey of three mental hospitals. Journal of Mental Science (1961) 107: 847-61.

2. E. M. Goldberg and S. L. Morrison, Schizophrenia and social class. British Journal of Psychiatry (1963) 109: 785-802.

3. G. L. Engel, The need for a new medical model: A challenge for biomedicine. Science (1977) 196(4286): 129-36.

4. N. Craddock, D. Antebi, M.-J. Attenburrow et al., A wake up call for British psychiatry. British Journal of Psychiatry (2008) 193: 6-9.

5. D. Pilgrim and A. Rogers, Social psychiatry and sociology. Journal of Mental Health (2005) 14(4): 317-20.

6. T. S. Kuhn, The Structure of Scientific Revolutions. Chicago: University of Chicago Press, 1962.

7. I. Illich, Limits to Medicine: Medical Nemesis: The Expropriation of Health. London: Maryon Boyars, 1976.

8. P. Bourdieu, The forms of capital. In J. Richardson, ed., Handbook of Theory and Research for the Sociology of Education, 241-58. New York: Greenwood, 1986. 
9. N. Rose, Inventing Our Selves: Psychology, Power and Personhood. Cambridge: Cambridge University Press, 1996.

10. F. A. Hayek, The Road to Serfdom. London: George Routledge \& Sons, 1944.

11. A. Clare, Psychiatry in Dissent. London: Tavistock Publications, 1976.

12. P. Bracken and P. Thomas, Postpsychiatry: A new direction in mental health. BMJ (2001) 322: 724-7.

13. M. Marmot and R. Wilkinson, Social Determinants of Health. Oxford: Oxford University Press, 1999.

14. R. Poole, R. Higgo and C. Robinson, Mental Health and Poverty. Cambridge: Cambridge University Press: 2014. 